\title{
Damage Investigation of a Tunnel Subjected to an Unplanned Surface Load Through Non-Linear Analysis
}

\author{
Oriol Arnau, Researcher; Climent Molins, Assoc. Prof.; Antonio Marí, Prof., Department of Civil and Environmental \\ Engineering, Universitat Politecnica de Catalunya, Barcelona, Spain. Contact: oriol@oriolarnau.com
}

DOI: $10.2749 /$ sei.1362

\begin{abstract}
A description of the deformations and damage that occurred in a segmental tunnel lining as a consequence of an unplanned surface load is presented, as well as the numerical analyses performed for its safety assessment. The tunnel in study is located in soft soil conditions and presents a low overburden. Few months after tunnel drilling, a new bridge was constructed at surface level, placing an access embankment over the tunnel path. Monitoring points were installed along the affected section which recorded the deformation of the tunnel caused by the embankment weight. More worryingly, despite no additional loads were introduced, the deformation of the lining continued increasing significantly along the next months, indicating the existence of soil consolidation phenomena. As a consequence, structural cracks emerged along the affected section. Non-linear finite element models that realistically simulate the behaviour of the non-linear segment joints and the concrete cracking were used to characterize the actual response and strength of the lining. The results showed that most significant damages should occur at the non-visible extrados side, and characterized how they evolve along the soil consolidation process. Finally, the adopted tunnel strengthening procedure is described.
\end{abstract}

Keywords: forensic engineering; segmental tunnel lining; soft soil; structural damage; non-linear analysis; soil-structure interaction; structural strengthening.

\section{Introduction}

When an abnormal response or a damage is detected in a structure it is of paramount importance to determine the causes and the possible

Peer-reviewed by international experts and accepted for publication by SEI Editorial Board

Paper received: August 8, 2016

Paper accepted: December 16, 2016 implications. Moreover, it is essential to answer key questions such as: whether the situation is stabilized or still evolving, if there exists a real risk of collapse and whether exceptional measures have to be taken in order to assure the structural stability.

The engineering approach for finding an appropriate response to these essential questions can be based on the analysis of the sensors data that reported the irregular response and/or the observed damage. Usually, an additional and more specific monitoring set-up is placed in the affected zone, about which recorded data could lead to a better explanation and determination of the problem. But, depending on the type or configuration of the affected structure, it could exist in several parts that are not visible or cannot be inspected, thus making impossible to adequately define the actual state of the structure. This situation is common in underground structures where it is not possible to directly evaluate the state of the extrados on direct contact with the ground, or in flooded structures in which service cannot be $100 \%$ interrupted like sewage tunnels or dams. Therefore, in these cases it would be necessary to estimate the possible damages in the un-surveyed zones in order to appropriately assess the actual state of the structure.

The interest of obtaining the maximum possible information is clear: a better knowledge about the causes for the abnormal response and a more complete definition of the actual situation in terms of damage would allow taking more appropriate decisions about the necessity and urgency of structural interventions. Moreover, better suited interventions could be proposed in order to solve the disorder.

Nowadays, modern modelling techniques can be used to study and comprehend the complex response of underground structures, to determine the causes of the problem, and to estimate the damage at non-visible sides. Advanced non-linear finite element models allow to realistically reproduce the main phenomena involved in the actual response of the structures, being capable of considering the cracking and plasticity of reinforced concrete, the response of the joints between different members, or the influence of the soilstructure interaction. Consequently, they can be used to simulate complex damage processes, evaluate the stress redistributions, estimate the actual state and the remaining capacity of the structure, and to adequately design intervention or retrofitting processes. Additionally, their repeatability permits easy analysis of different scenarios and conditions, allowing to determine the most influencing parameters, or to test different parameter values in order to cover possible uncertainties (materials, loads, etc.).

This paper presents the study and analysis of a Barcelona L9 tunnel section that presented significant movements that originated following the placement of a new bridge embankment on (Fig. 1). Initial deformation measurements continuously became larger over time despite no other loads were introduced on the surface, indicating a soil consolidation phenomenon. Consequently, large deformations were experienced by the segmental tunnel lining, also presenting significant cracking at the intrados of the tunnel. The situation at the time of study is initially exposed, and the movements and damages registered are then described. Later, twodimensional (2D) non-linear numerical models that appropriately considered the joints, the soil-structure interaction, and the inelastic response of constituent materials, are defined in order to reproduce the structural response of the segmental rings at the damaged section. Actual measurements and damage observations are used to validate the adopted modelling strategies and values. Numerical model results are presented and discussed, showing how they can contribute towards comprehending the causes of damages and the main governing mechanisms, to characterize 
the actual state of the lining, and to estimate the damages at the non-visible extrados side. Finally, the adopted tunnel strengthening procedure is described, and main conclusions are presented.

\section{Case Study}

The studied section is located at Barcelona's Line 9 metro tunnel. The tunnel was constructed by means of a tunnel boring machine (TBM) and presents an internal diameter of $8.43 \mathrm{~m}$. A $320 \mathrm{~mm}$ thick precast concrete segmental tunnel lining was used as a unique resisting structure, which was composed by six conventional segments plus one key segment. The construction of the tunnel was finished without remarkable incidences.

Few months after the tunnel drilling, a new road was planned in the case study zone, including a new bridge and a new access from an existent road. As it can be observed in Fig. 1, this new infrastructure implied the placement of embankments over the tunnel path, which achieved a maximum height of around $7 \mathrm{~m}$ over the original level at the bridge access.

At the studied section, the tunnel runs through a geological layer of silt and clay (QL3), presenting an average depth of 25 to $30 \mathrm{~m}$ (see Fig. 1). The top of the tunnel is placed at the interface to a sand layer (QL2), which is preceded by a thin silt-clay layer (QL1) and an initial fill layer (F). The total original overburden of the tunnel was around $15.3 \mathrm{~m}$, whilst the groundwater table was located at $4 \mathrm{~m}$ depth. The basic properties of the soil layers are listed in Table 1.

In order to record the movements of the tunnel during the embankments construction, five different sections were initially instrumented by means of three topographic prisms (sections $\mathrm{S} 1$ to S5 in Fig. 1), located around the crown and at the mid-height point of the tunnel (see Fig. 2 indicators). The monitoring process started on 18 December 2008 and the embankments were erected in January 2009 (as seen in Fig. 2). Two more prisms were added to the bottom part of the monitored sections (starting at 19 March 2009) in order to obtain a more complete information about the increasing deformation of the lining.

Displacement records clearly showed that, despite no further loads were applied on the surface, the deformation of the lining was continuously increasing in the following months. As can be observed in Fig. 2a, maximum vertical crown movements increased from around $18 \mathrm{~mm}$ at the time of end of construction to above $80 \mathrm{~mm} 8$ months later, thus defining an increase of over $300 \%$ in the lining deformation without performing any action. Slightly higher deformation increments were observed in the lateral deformation (Fig. 2b), increasing from around $4 \mathrm{~mm}$ to over $35 \mathrm{~mm}$, and defining an increment above $700 \%$.

The segmental tunnel lining presented a significant cracking at the crown intrados, as can be observed in Fig. 3 for the rings compressed between the instrumented sections S3 and S4 (see Fig. 1). Maximum crack widths were always registered at the sections weakened by the lifting and grouting holes of the segments (indicated with circles in Fig. 3), achieving a maximum of $1 \mathrm{~mm}$ at ring 237 (the crack runs across the whole segment in the longitudinal direction of the tunnel). Along the complete sections, crack widths of 0.1 and $0.2 \mathrm{~mm}$ systematically appeared, achieving $0.3 \mathrm{~mm}$ width in the majority of the rings along the affected zone (see rings 232 and 235 in Fig. 3 as example). The maximum value registered at a complete section was around $0.5 \mathrm{~mm}$, as can be observed at the crown central part of ring 235 (Fig. 3).

The crack patterns registered also showed different intensities and location depending on the position of the longitudinal joints, thus indicating a clear influence of the ring configuration in the damage generation.

Studies performed by local geological specialists indicated that the most feasible cause for the long-term deformations experienced by the lining could be found in a consolidation phenomenon experimented by the soil, since no significant additional loads were placed at the surface. According to the consolidation principle, when a saturated stratum like clayey soil is subjected to a stress increase (like the one caused by the embankment weight, or by the tunnel's own deformation), the excess of pore water pressure is slowly dissipated due to the relatively low permeability of the

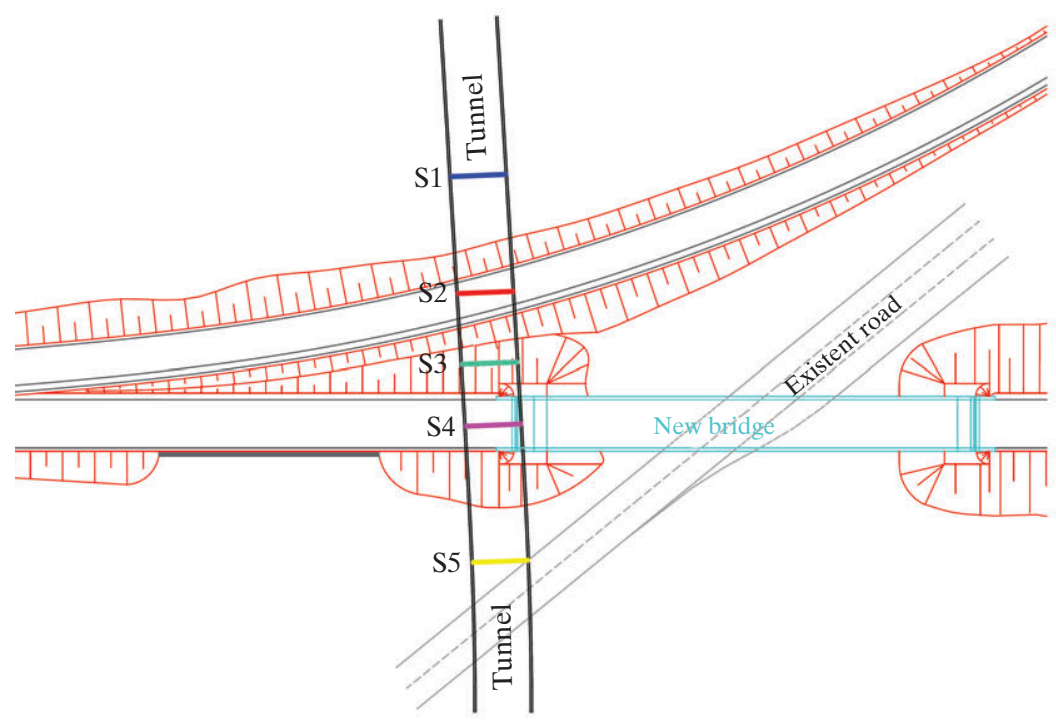

Fig. 1: Description of the case study: top view and soil section (Unit: $m$ )

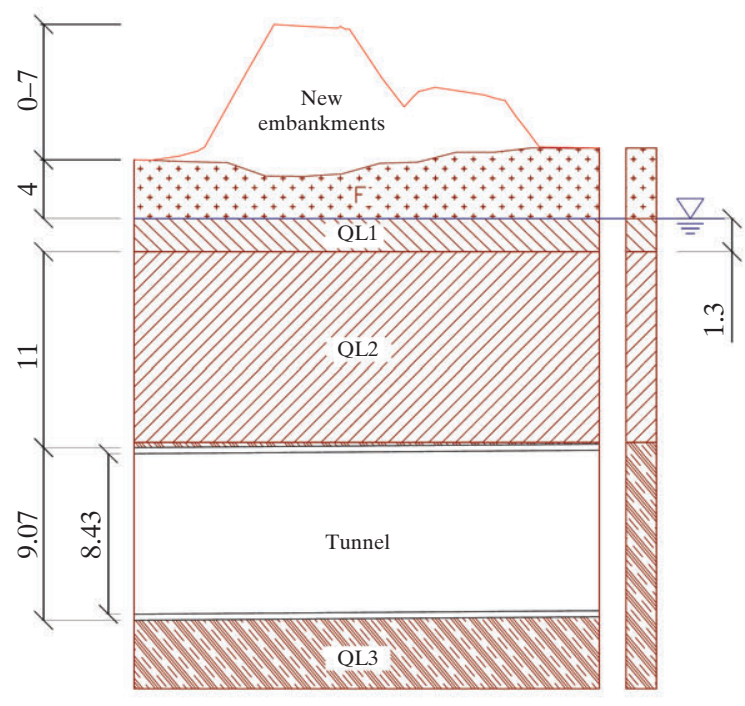




\begin{tabular}{|c|c|c|c|c|c|}
\hline Layer & $\begin{array}{c}\text { Modulus of } \\
\text { elasticity, } \\
\mathbf{E}^{\prime}\left(\mathrm{N} / \mathrm{mm}^{2}\right)\end{array}$ & $\begin{array}{c}\text { Total or } \\
\text { submerged } \\
\text { density, } \\
\gamma^{\prime}\left(\mathbf{k N} / \mathbf{m}^{3}\right)\end{array}$ & $\begin{array}{c}\text { Poisson } \\
\text { coefficient, } \\
\nu\end{array}$ & $\begin{array}{r}\text { Cohesion, } \\
\mathbf{C}^{\prime}\left(\mathbf{k N} / \mathrm{m}^{2}\right)\end{array}$ & $\begin{array}{c}\text { Friction } \\
\text { angle, } \\
\varphi^{\prime}\left({ }^{\circ}\right)\end{array}$ \\
\hline Fill $(\mathrm{F})$ & $3-5$ & $18-19(\mathrm{~T})$ & 0.3 & - & $25-27$ \\
\hline $\begin{array}{l}\text { Silt clay } \\
\text { (QL1) }\end{array}$ & $9-15$ & $10.1(\mathrm{~S})$ & 0.3 & 5 & 29 \\
\hline Sand (QL2) & 20 & $10.1(\mathrm{~S})$ & 0.3 & 5 & $31-32$ \\
\hline $\begin{array}{l}\text { Silt clay } \\
\text { (QL3) }\end{array}$ & $\begin{array}{c}12-30 \\
\text { (depth } \\
\text { depending) }\end{array}$ & $12.0(\mathrm{~S})$ & 0.35 & $5-15$ & $25-32$ \\
\hline
\end{tabular}

Table 1: Basic characteristics of the soil at the site ${ }^{1}$

soil, may also causing adjustments in the internal structure of the soil particles. As a consequence, the pressure increment caused by the embankment weight over the top of the ring could become gradually higher than in the lateral sides, thus producing a more unbalanced loading pattern as time goes by.

For perfectly hydrostatic load conditions (i.e., constant radial pressure applied at the tube section), tunnels should only be subjected to compression forces, but out of these ideal

(a)

conditions, bending moments and deformations emerge. Segmental tunnel linings are multiple-hinged structures that require the reaction of the surrounding soil to find the equilibrium. For soft-soil conditions, significant soil deformations are required in order to produce the reaction forces, thus originating significant displacements in the rings even for low hydrostatically unbalanced loads. Therefore, it is of paramount importance to find out the structural implications of the ovalization distortion increase (from circular to oval form) suffered by the segmental

Date

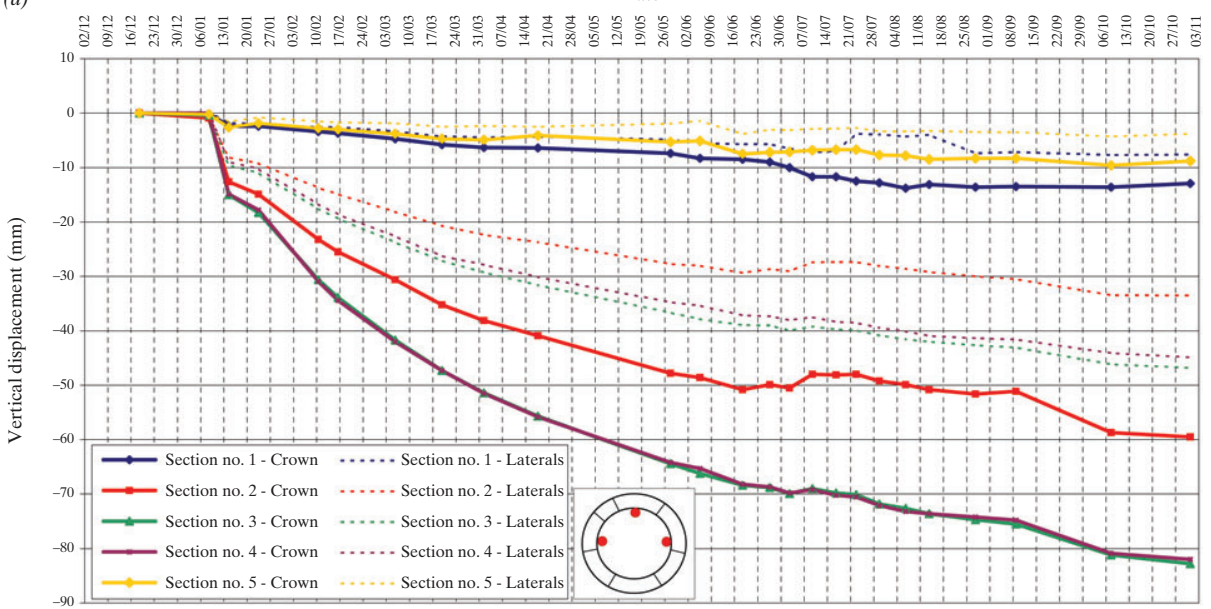

(b)

Date

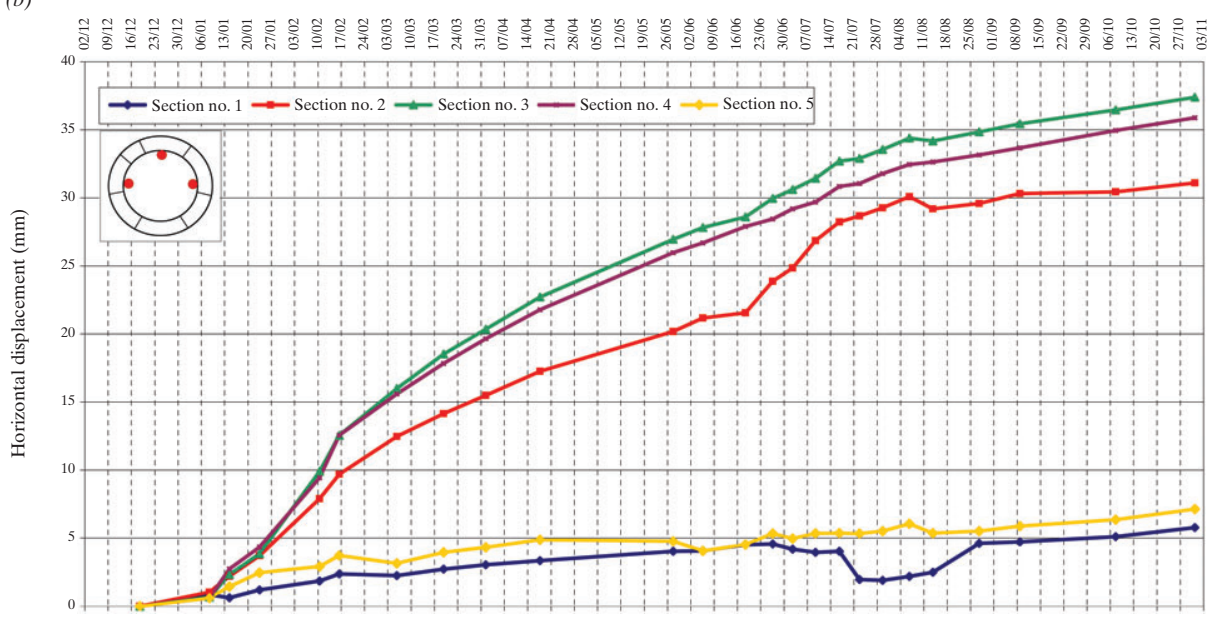

Fig. 2: Vertical and horizontal displacements recorded at the instrumented sections tunnel linings as a consequence of the consolidation phenomenon.

\section{Numerical Analyses}

This section gives the numerical reproduction of the structural response of the Line 9 segmental tunnel lining following the positioning of the new embankment and the progressive reduction of the lateral earth pressure caused by the consolidation process.

A 2D plane stress model is used for such purpose, which can be seen in Fig. 4. The height of the segments is divided in seven regular quadrilateral elements, defining a complete model presenting 4186 elements. The concrete properties and inelastic response are adopted from the Model Code $90^{3}$ through an automatic option available in the software ${ }^{4}$ assuming a C40 class concrete and using the Total Strain Crack Model. A Von Misses plasticity model is used to reproduce the embedded steel reinforcement, adopting a modulus of elasticity of $200000 \mathrm{~N} / \mathrm{mm}^{2}$ and a yielding stress of $500 \mathrm{~N} / \mathrm{mm}^{2}$. Perfect bond is considered between both materials.

The unilateral response of the $206 \mathrm{~mm}$ in height joints is modelled through interface elements (shown in violet in Fig. 4) that do not present tensile stiffness, as proposed in Ref. 5. The soilstructure interaction is considered through radial and tangential springs related to each one of the external nodes of the mesh, as shown in Fig. 4. When external loads are applied to the numerical model, they produce the movement and deformation of the tunnel since the ground reaction is provided by the springs. In order to avoid the unrealistic pull of the tunnel to the ground that can be obtained at certain tunnel zones, non-linear radial springs with no tensile stiffness are used. The radial stiffness value is determined from the modulus of elasticity of $E_{s}=15 \mathrm{~N} / \mathrm{mm}^{2}$ specified in the project document for the soil layer containing the tunnel at the axis depth (Table 1), using the equation of a circular beam in elastic media (Eq. 1), and assuming a tangential stiffness of $1 / 3$ of the radial stiffness ${ }^{6}$ (Eq. 2).

$$
\begin{aligned}
K_{r} & =\frac{E}{R \cdot(1+\nu)} \\
K_{t} & =\frac{K_{r}}{3}
\end{aligned}
$$




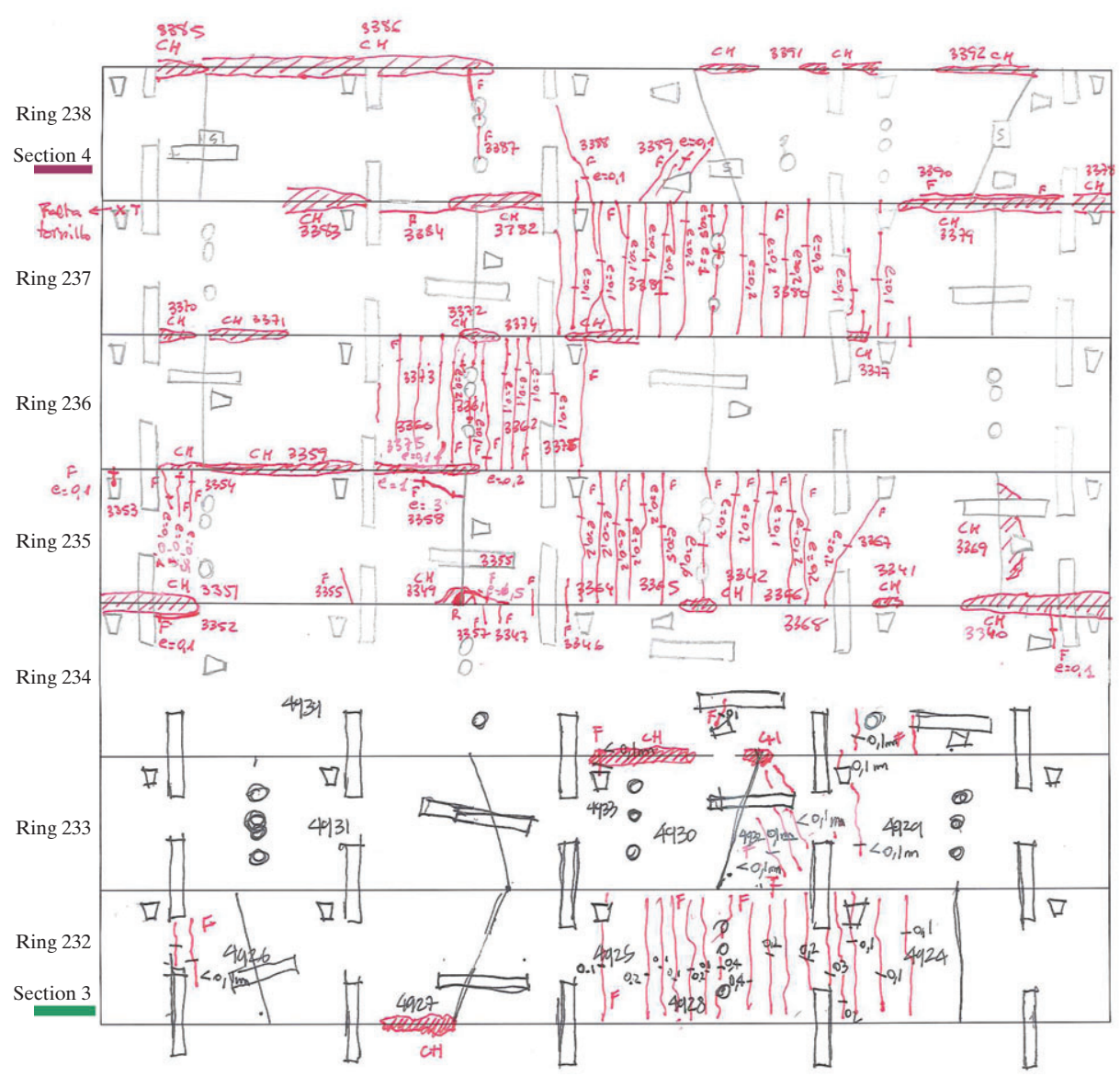

Fig. 3: Survey of cracking of the rings between instrumented sections $S 3$ and $S 4^{2}$

In the absence of experimental evidences of the actual soil and water pressures acting on the studied tunnel section, the initial loading of the ring was determined according to the ground section and characteristics presented in Fig. 1 and Table 1, respectively. The calculated vertical and horizontal soil pressures are introduced in the model through nodal forces applied at the outer surface of the tunnel. The original conditions are introduced in the first load step, whilst the pressure created by the embankment is

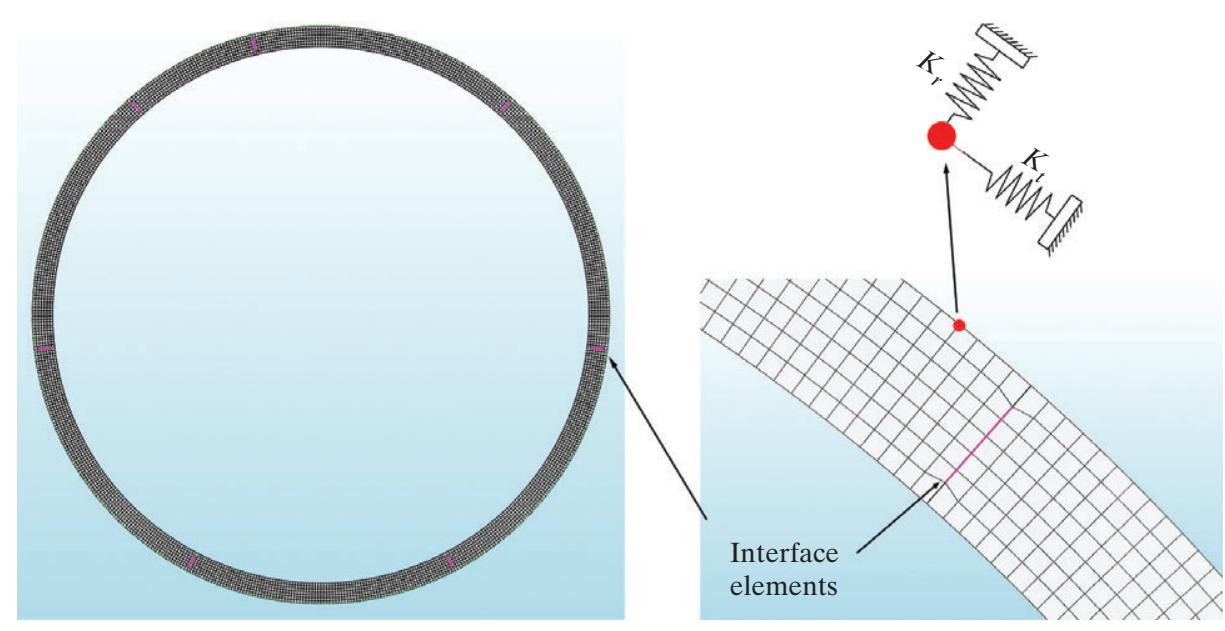

Fig. 4: Segmental ring: numerical model convergence criterion of $0.05 \%$ in energy.

According to the definition of universal ring type used in this section of Line 9 tunnel, the ring presents a certain conical form that produces variable width of the ring. This geometry allows defining the tracking of the tunnel by modifying the relative position between the rings. In this particular case, 13 different ring placements are possible in order to create turns and depth variations. This originates different possibilities of joint locations in respect of the load position, as it can be observed in Fig. 5 . Joints present a significant influence in the structural response of segmental tunnel lings and, therefore, different structural responses can be presented for different joint positions. A numerical study using linear material properties was carried out over the most common configurations presented along the damaged section. Position 13 (Fig. 5a) emerged as the joint position configuration that represents a stiffer response of the ring, thus providing the smallest displacements but the highest bending forces. Position 12 (Fig. 5b) behaves in the opposite way, thus defining the most flexible option for the same loading. Consequently, non-linear analyses were performed over both configurations in order to cover a wide range of possible responses.

Figure $6 a$ and $c$ presents the vertical displacement at the crown and the maximum horizontal displacement numerically obtained for joint positions 13 and 12 (Fig. 5) when reducing $K_{0 \mathrm{f}}$. As can be observed, ring joint position 12 presents a more flexible response to the applied load than position 13, increasing $12 \%$ the vertical displacement at the crown $(114 \mathrm{~mm}$ in front of $102 \mathrm{~mm})$ and $57 \%$ the maximum horizontal displacement $(63 \mathrm{~mm}$ in front of $40 \mathrm{~mm}$ ) when $K_{0 \mathrm{f}}$ turns 0 . Consequently, for the stiff ring configuration (Fig. 6a), the registered vertical displacement at the crown (Fig. 2) would be achieved at $K_{0 \mathrm{f}}=0.2$, whilst maximum horizontal displacement at $K_{0 \mathrm{f}}=0.05$. For the flexible configuration (Fig. 6b), these points are found at $K_{0 \mathrm{f}}=0.31$ and $K_{0 \mathrm{f}}=0.27$ respectively, thus indicating that the proposed load configuration for reproducing the complex consolidation phenomenon tends to slightly 
underestimate the actual lateral displacements of the ring.

These results clearly show the significant influence that the position of the longitudinal joints (between two adjacent segments of a same ring) has on the structural response of segmental tunnel rings. Concentrated rotations occur at longitudinal joints when rings deform and, depending on their relative positions in front of the load, the structural system can present a stiffer or more flexible response (presenting higher or lower deformation). This phenomenon could be especially relevant in soft-soil conditions, where larger ring deformations can be presented until the soil provides the necessary reaction to equilibrate the acting loads. Additionally, they also point out the difficulty to estimate the actual response of a tunnel section as a compendia of different ring positions, more so when the interaction between adjacent rings and the threedimensional response of the lining is not considered. ${ }^{7-9}$ Therefore, a complete range of $K_{0 f}$ varying from 0.31 to 0.05 has to be studied in order to cover the possible scenarios affecting the actual tunnel state at the last registering date (Fig. 1).

As can be observed in Figs. $6 d$ and $7 b$, the inner reinforcement is the one in most demand in terms of stress in the flexible ring configuration. It rapidly achieves a value of about $300 \mathrm{~N} /$ $\mathrm{mm}^{2}\left(K_{0 \mathrm{f}}=0.4\right)$, but later it presents a stable response around this value up to the complete elimination of $K_{0 \mathrm{ff}}$. The external reinforcement does not present significant activity since $K_{0 \mathrm{f}}$ approaches 0.35 (hence denoting the initiation of concrete cracking at the extrados), progressively increasing to $170 \mathrm{~N} / \mathrm{mm}^{2}$ (Fig. $6 d$ ) for $K_{0 \mathrm{f}}=0$. This response could indicate that, for such particular configuration, the deformation of the ring would be based more on the rotation of the longitudinal joints than on the opening of the cracked sections, as can be seen in Fig. $7 b$.

The concrete and reinforcement stresses at the most unfavourable sections are used to determine the crack width $\left(w_{k}\right)$ at both intrados and extrados sides according to Eurocode 2. ${ }^{10}$ As can be observed in Fig. $6 d$, the crack width expected at the intrados side (crown) should be in the range of 0.2 to $0.3 \mathrm{~mm}$, which perfectly fits the actual measures in the survey presented at the case study description (Fig. 3).
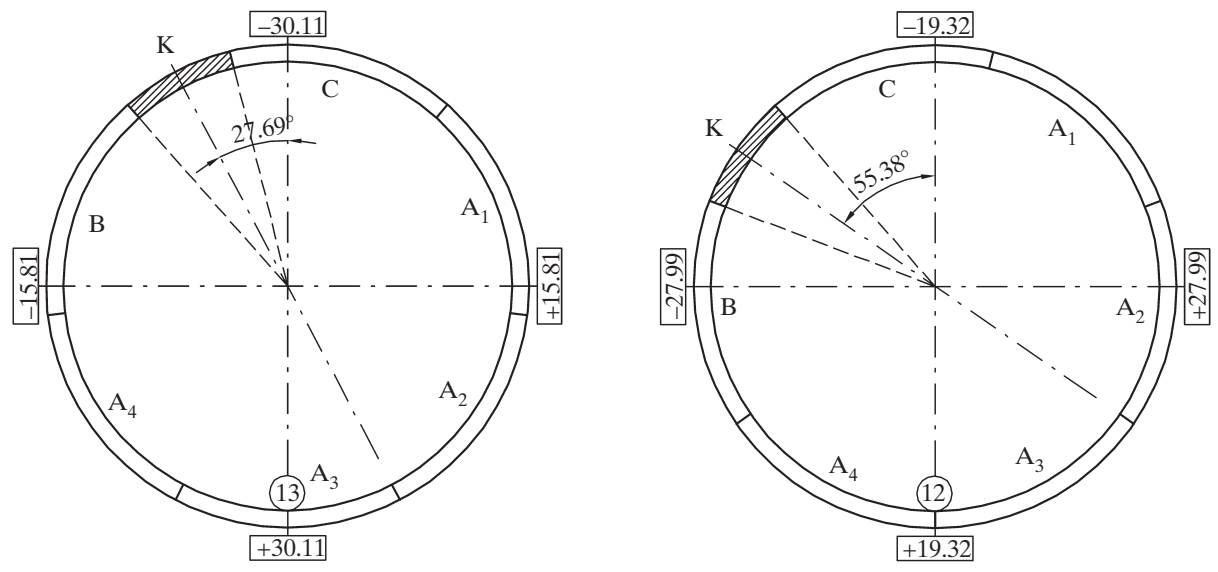

Fig. 5: Analysed joint position configurations ${ }^{1}$

When analysing the maximum reinforcement stresses obtained for the stiff ring configuration (Fig. 6b), it can be seen how both internal and external reinforcements easily scale up to $300 \mathrm{~N} / \mathrm{mm}^{2}\left(K_{0 \mathrm{f}}=0.4\right)$. From this point, the decrease of $K_{0 f}$ does not produce a relevant stress increase at intrados reinforcement at the crown, but significant increments occur at the extrados reinforcement at the haunches, achieving the steel yielding stress for $K_{0 f}=0.05$ (view also Fig. 7a). Consequently, it has to be considered that, for the last registered ring movements, it would be possible that the extrados reinforcement could have achieved the plastic regime or could be close to.

These stress states define intrados crack openings at the tunnel crown as around $0.25 \mathrm{~mm}$ for all values of $K_{0 \mathrm{f}}$ under 0.4 (Fig. 6b), which equals the flexible configuration results, and are also completely consistent with the damage survey presented at the case study description (Fig. 3). On the other hand, maximum extrados crack opening significantly increases with the decrease of $K_{0 f}$, achieving an opening of around $0.4 \mathrm{~mm}$ for the last registered situation.

This response indicates that, for the stiff ring configuration, the deformation of the ring demands local rotations at the cracked sections of the haunches, thus concentrating the damage at the extrados. Figure $7 a$ clearly shows wide concrete damage zones at the haunches (orange-red), as well as the ascension of the section neutral axis, and the increment of the compression stress at the intrados. Consequently, maximum steel reinforcement stresses and crack openings could be located at the non- visible side, which is in contact with the soil, and do not allow appropriate survey or repair. In consequence, external reinforcement could be potentially affected by durability problems along its service life, fact that has to be considered when designing the strengthening of the lining.

\section{Proposed Strengthening}

The objective of the strengthening of the existing lining was to provide enough structural capacity to resist long-term scenario, whilst improving the stiffness in order to avoid excessive deformations that could affect the serviceability of the tunnel. For adequately defining the long-term damage scenario, it was considered that the effect of the corrosion on the reinforcement at the cracked extrados subjected to the aggressiveness of soil and water in contact with the tunnel could lead to a reduction of $50 \%$ of the reinforcements' section. The authors carried out verifications to ensure that the flexural capacity of the enlarged section, assuming the $50 \%$ loss of steel reinforcement, was equal or greater than that of the original intact section. The constructive design of the strengthening intervention was carried out by an engineering consulting company, on the basis of the presented conclusions and recommendations, using more conventional tools for the structural analyses and mandatory code checks.

The strengthening consisted essentially of enlarging the depth of the lining of the tunnel, by adding a continuous layer of $200 \mathrm{~mm}$ of reinforced sprayed concrete connected to the existing tunnel structure, in order to provide enough stiffness and capacity to the 
lining, preventing further deformations and cracks in the long term. The characteristic compressive strength of the sprayed concrete was $30 \mathrm{~N} / \mathrm{mm}^{2}$. To prevent early-age cracking of the lining due to thermal and shrinkage strains, circumferential joints were placed every $7.5 \mathrm{~m}$ or less, corresponding to five segments, in the longitudinal direction. This was consistent with the designed behaviour of the strengthening as a ring.

A single layer of reinforcement was placed close to the intrados with a cover of $50 \mathrm{~mm}$, composed by circumferential $10 \mathrm{~mm}$ rebars at $150 \mathrm{~mm}$ and longitudinal $8 \mathrm{~mm}$ rebars at $250 \mathrm{~mm}$. The reinforcement also included connections made of steel dowels to improve the shear-friction capacity, distributing two dowels of $10 \mathrm{~mm}$ diameter (forming one U-shaped rebar) every $400 \times 400 \mathrm{~mm}$. This Ureinforcement was inserted $200 \mathrm{~mm}$ into the existing segmental lining for a good anchoring. Sand blasting was also applied in the intrados surface before spraying concrete to reduce rebound and to improve shear-friction capacity.

The strengthening was applied in 2010 and since then no new cracks and no relevant increments of deformations have been observed.

\section{Conclusions}

The study and analysis of the abnormal response and damages that appeared in the tunnel section in this case study pointed out the following:

- The increasing deformations and damages observed at the interior of the lining were mainly caused by the construction of a new embankment over the tunnel path, and the related consolidation phenomenon experienced by the soft soil surrounding the tunnel.

- Internal surveys and measurements could not be enough to adequately define the actual situation of an underground structure presenting an abnormal response and/or damages, since the structural state at non-visible sides (extrados in contact with the soil) cannot usually be directly characterized.

- Non-linear advanced numerical models, and their capacity for reproducing the actual inelastic response of the constitutive materials and joints, emerge as necessary tools in order to determine the causes of the damages, comprehend the main governing mechanisms, and to evaluate the actual state of the structure. In the present work, the results of such models helped to understand and characterize the influence of the joint positions in the structural system stiffness, and in the damage evolution process. In this case study, maximum variations of 12 and $57 \%$ were obtained at the vertical displacement at the crown and maximum horizontal displacements by varying only the ring joint positions.

- In the case study, numerical simulations demonstrated that the maximum structural damage could be located at the extrados side, being practically impossible to be directly evaluated or repaired. For the stiff

Ring joints position 13 (stiff configuration)

(a)

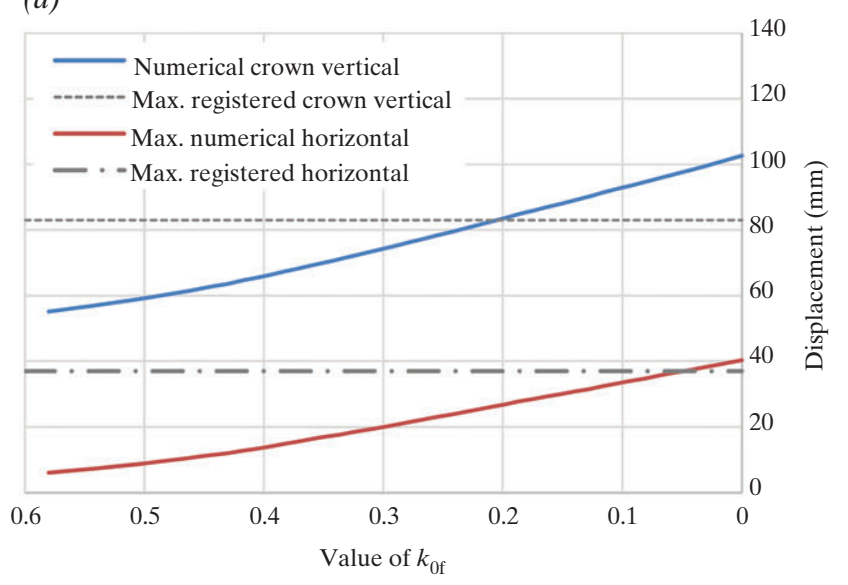

(b)

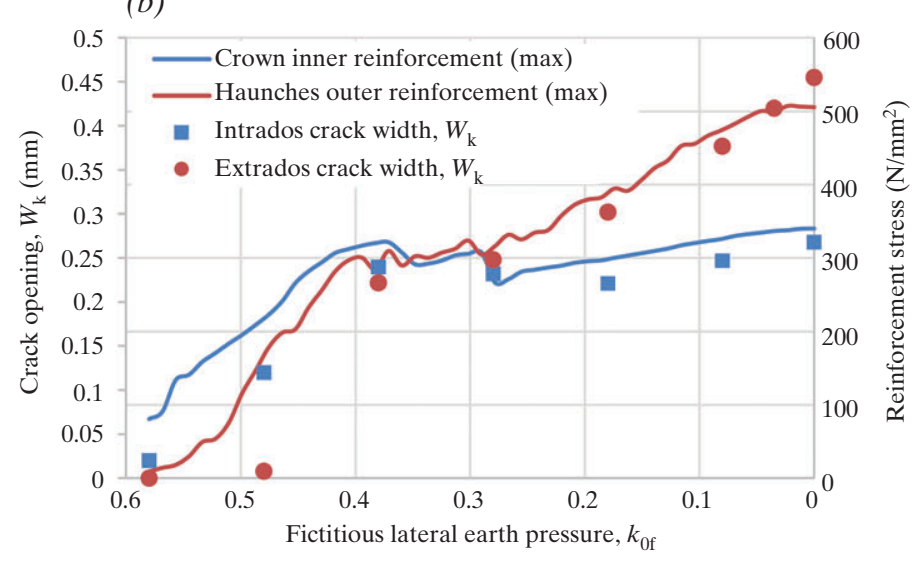

Ring joints position 12 (flexible configuration)

(c)

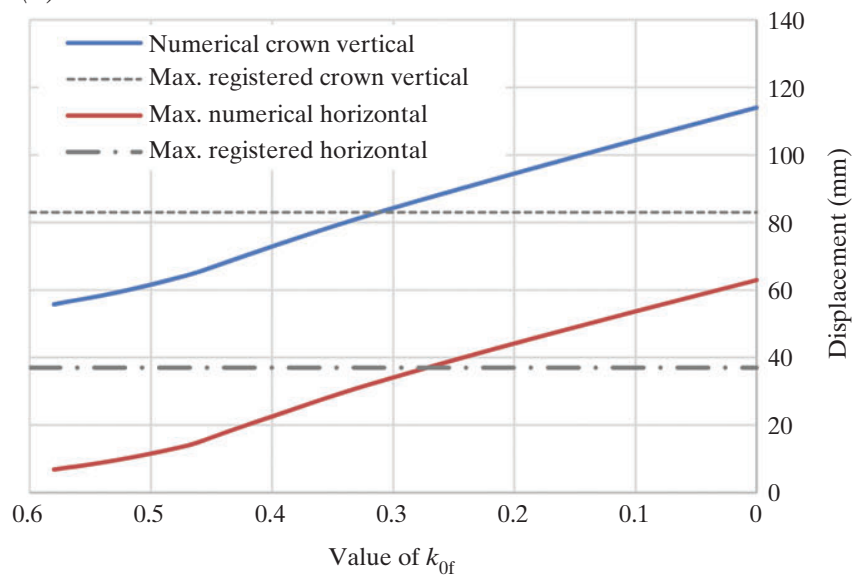

(d)

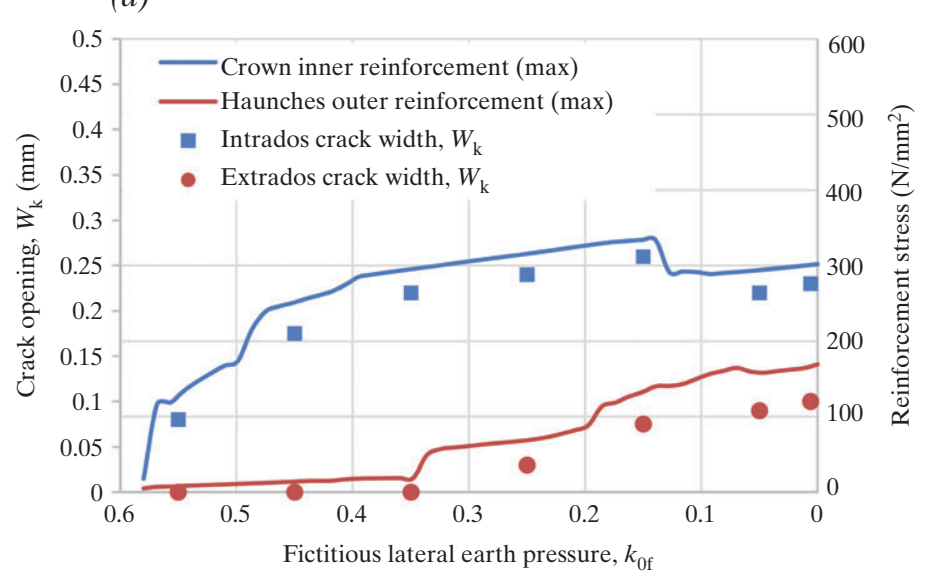

Fig. 6: Structural response of the lining when reducing $K_{\text {of }}$ for the two simulated configurations 


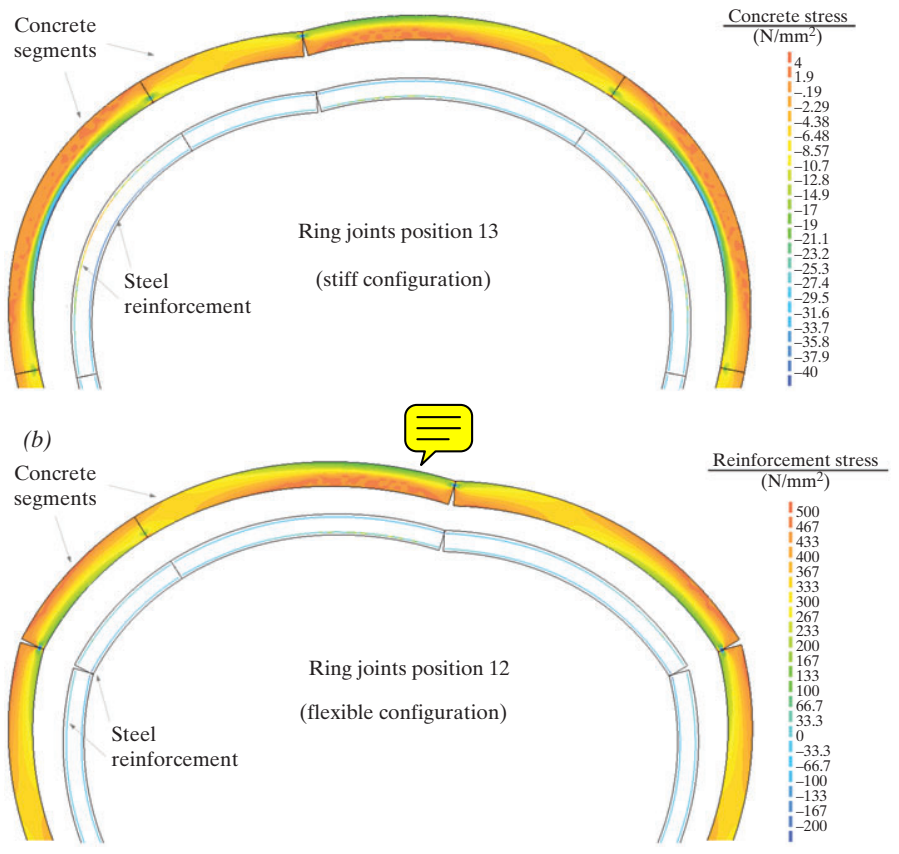

Fig. 7: Circumferential stress state for $K_{0 f}=0.1$; deformation factor $=10$

ring configuration analysed, average crack opening at the intrados side should be located around $0.25 \mathrm{~mm}$, which is fully consistent with the information reported in the damage survey. At the extrados side, the average crack opening for the last registered deformations could be located around $0.4 \mathrm{~mm}$, obtaining a maximum reinforcement steel stress close to its yielding value. Therefore, for the last registered ring movements, extrados reinforcement steel could have achieved the plastic regime or could be close.

- The most complete knowledge about the causes of the damage and about the actual state of the structure achieved by using advanced numerical models allows taking appropriate decisions about further actions to take, more so to design better interventions and retrofitting processes. In this case study, the conclusions about the possible wide crack openings at the extrados side led to appropriately consider the cracking and the longterm corrosion of the reinforcement in the design of the strengthened section.

\section{Acknowledgements}

The present work was carried out in the framework of the contract subscribed between the Technical University of Catalonia (UPC) and the public company Infraestructures de la Generalitat de Catalunya SAU for research and innovation in the construction of Line 9 of the Metro of Barcelona.

\section{References}

[1] Line 9 Metro of Barcelona. Project documents (in Catalan)

[2] COTCA. Damage categorization of a Line 9 tunnel section (in Catalan), 2009.

[3] CEB-FIP. CEB-FIP Model Code 1990. Thomas Telford: London, 1993.

[4] TNO. Diana user's manual. Release 9.4, 2009. http://www.tnodiana.com

[5] Arnau O, Molins C. Experimental and analytical study of the structural response of segmental tunnel linings based on an in situ loading test. Part 2: Numerical simulation. Tunn. Undergr. Space Technol. 2011; 26: 778-788.

[6] Molins C, Arnau O. Experimental and analytical study of the structural response of segmental tunnel linings based on an in situ loading test. Part 1: Test configuration and execution. Tunn. Undergr. Space Technol. 2011; 26: 764-777.

[7] Arnau O, Molins C. Three dimensional structural response of segmental tunnel linings. Eng. Struct. 2012; 44: 210-221.

[8] Arnau O, Molins C, Blom CBM, Walraven JC. Longitudinal-time dependent response of segmental tunnel linings. Tunn. Undergr. Space Technol. 2012; 28: 98-108.

[9] Arnau O, Molins C. Theoretical and numerical analysis of the three dimensional response of segmental tunnel linings subjected to localized loads. Tunn. Undergr. Space Technol. 2015; 49: 384-399.

[10] CEN. EN 1992-1-1, Eurocode 2: Design of Concrete Structures, Part 1-1: General Rules and Rules for Buildings CEN: Brussels, 2004. 